\title{
Interacting effects of high temperature and drought stresses in wheat genotypes under semiarid tropics- an appraisal
}

\author{
Vikender KaUR', Rishi Kumar BeHL ${ }^{1, *}$, Takuro ShINANo ${ }^{2}$ and Mitsuru OsakI ${ }^{3}$ \\ Department of Plant Breeding, CCS HAU, Hisar 125 004, Haryana, India \\ National Agricultural Research Center for Hokkaido Region, Sapporo 062-8555, Japan \\ ${ }^{3}$ Graduate School of Agriculture, Hokkaido University, Sapporo 060-8589, Japan \\ *Corresponding author: Tel: +91-1662-289135, E-mail: rkbehl@hau.ernet.in
}

\begin{abstract}
The production of wheat is one of the most important breeding targets in India. The major constraints in the productivity are based on the limiting usage of water. In this mini-review, the focus is on the physiological traits of wheat plants to obtain the tolerance against heat and drought stress. This will encourage the breeding program on wheat in semi arid tropics like India.
\end{abstract}

Key words: drought stress, India, water deficient, wheat

\section{INTRODUCTION}

Among different crop species wheat (Triticum aestivum L.) is one of the most important cultivated species. Yield potential of any variety is the combined effect of genotype and environmental interaction. Now a days global warming and scarcity of water are important factors for the wheat production throughout the world. In the last century, carbon dioxide concentration $\left(\mathrm{CO}_{2}\right)$ has risen rapidly from about $350 \mu \mathrm{mol} \mathrm{mol}^{-1}$ in 1980 to about $378 \mu \mathrm{mol} \mathrm{mol}^{-1}$ at present. At the current rate of gas emissions and population increase, it is predicted that $\mathrm{CO}_{2}$ will double by end of this century. These changes in $\mathrm{CO}_{2}$ and other greenhouse gases are predicted to increase surface mean temperature in the range of $1.4-5.8^{\circ} \mathrm{C}$. In addition, studies also show that in future climates will have more frequent short spells of high temperature (heat). Most crops are highly sensitive to heat stress and often result in progressively decreasing yields at temperatures above the optimum. Howard (1924) while analyzing the factors controlling wheat production remarked that "wheat production in India is a gamble in temperature". This statement is valid even today. The cultivation of wheat is limited by abiotic stresses (moisture and temperature). The present day rice-wheat cropping system and irregularities in monsoon have compelled wheat crop to face rapidly ascending temperatures coupled with moisture stress during the post-anthesis stages. These unfavorable environmental conditions severally affect post-anthesis stages and ultimately reduce yield considerably. It has already been established that stress due to high temperature can play significant role in reducing yield and quality of wheat (Stone and Nicolas, 1995). Wheat yields are reduced by $50-90 \%$ of their irrigated potential by drought on at least 60 million ha in the developing world (Reynolds et al. 2001). Breeding for heat and moisture stress tolerance forms an integrated component of wheat breeding programme at both national and international level (Acevedo et al. 1990). One of the most important and economic ways to overcome negative effects of heat stress is to identify and/or develop heat-tolerant cultivars. At present, the major constraint for identifying heat-tolerant cultivars is the lack of reliable screening tool. Better understanding of the possible impact of high temperature stress on physiological, morphological, and yield processes would not only help in mitigating the adverse effects of high temperature stress but also in developing reliable fieldscreening tools (Singh et al. 2007). The present paper is an attempt to have an appraisal to understand the effects on morpho-physiological traits under high temperature and moisture stress conditions so that yield targets can be met out under changing conditions.

\section{WATER RELATIONS}

\section{High temperature stress}

Heat, as a stressor, adversely affects water status of the plant. Relative water content and excised leaf weight loss appeared to be one of the important characters as the varieties having better resistance also had better performance under high temperature and drought stress 
(Dhanda and Sethi, 2004).High temperature and its effects on plant water relations were also reported by Machado and Paulsen (2001) and Deng Xi-Peng et al. (2005).

\section{Drought}

Relative water content has been reported as an important indicator of water stress in leaves, it closely reflects the balance between water supply to the leaf and transpiration rate (Lilley and Ludlow, 1996). This influences the ability of the plant to recover from stress which consequently affects yield and yield stability. Assessment of water loss from excised leaf weight loss has shown promise for characterizing drought resistance in wheat genotypes (Clarke, 1987; McCaig and Ramagosa, 1991). This trait is moderately heritable (Clarke and Towney-Smith, 1986) and can be easily determined in a large population (Dhanda and Sethi, 1998). Following excision, stomata close and after 20-30 min., the rate of water loss enters a linear phase that lasts for several hours (McCaig and Ramagosa, 1991). During this phase the water is lost from incompletely closed stomata. Sinclair and Ludlow (1986) noted that there is no conclusive proof that stomata of excised leaves are fully closed. Consequently, Clarke and Richards (1988) proposed to use the term residual transpiration, defined as the rate of water loss from excised leaves at minimum stomatal aperture, in place of cuticular transpiration. Excised leaf water loss was related to drought resistance in wheat (McCaig and Ramagosa, 1991; Dhanda et al. 1998), but its relationship was not consistent on various stages of plant growth (Dhanda, 1993; Dhanda et al. 1995). Recently, Dhanda et al. (2007) have reviewed wheat improvement under water deficit conditions in semi arid tropics and sub tropics.

\section{High temperature and drought stresses}

Shah (1992) reported that simultaneous heat and drought stresses reduced leaf water content, water potential and osmotic potential in wheat. Wheat and sorghum crops maintained nearly stable water relations regardless of temperature when moisture was ample, but high temperature strongly affected water relations when water was limiting. The combined stresses strongly reduced soil water content, leaf relative water content, leaf water potential and leaf osmotic potential (Machado and Paulsen, 2001).

\section{PROLINE}

\section{High temperature stress}

The accumulation of proline in a variety of species under various kinds of stresses and its possible involvement in adaptive mechanisms has been reviewed by Aspinall and Paleg, (1981). Unlike the participation of proline and other free amino acids in the response to drought, their role during high temperature stress has not been studied so intensively. The protective role of proline during high temperature stress was shown in cotton, since cultivars with high proline content suffered less damage during heat stress (Ashraf et al. 1994). The involvement of free amino acids in response to heat stress was shown in spring wheat, where a mutant having greater amino acid contents (especially serine, methionine, histidine and arginine) was damaged to a lesser extent after heat stress treatment than the parent genotypes (Behl et al. 1991).

\section{Drought}

Free proline has been suggested as a metabolic measure of drought, and to play an important role as an organic osmolyte. Osmotic adjustment is an important acclimation mechanism which could allow for the maintenance of relatively greater metabolic functions at low leaf water potential (Laurie et al. 2002; Gilliham and Tester, 2005). An increasing number of reports provide evidence on the association between high rate of osmotic adjustment (OA) and sustained yield or biomass under water limited conditions across different cultivars of crop plants. Since $\mathrm{OA}$ helps to maintain higher leaf relative water content (RWC) at low leaf water potential (LWP), it is evident that OA helps to sustain growth while the plant is meeting transpirational demand by reducing its LWP. Osmotic adjustment is a major cellular stress adaptive response in certain crop plants that enhances dehydration avoidance and supports yield under stress (Blum, 2005). Nayyar and Walia (2003) demonstrated adaptive role of proline during drought stress. They observed a higher rate of proline accumulation and utilization during water-deficit in a drought tolerant wheat genotype C 306 compared to a drought sensitive HD 2380. The involvement of proline in the response to water shortage was also demonstrated in transgenic tobacco over expressing an enzyme of proline biosynthesis, ornithine amino- $\Delta$-aminotransferase. These transgenic plants exhibited higher proline levels and improved drought tolerance (Roosens et al. 2002). An increase in the content of proline in leaves of transgenic potato lines was noticed under water stress by Knipp and Honermeier (2006).

\section{High temperature and drought stresses}

The effect of simultaneous drought and heat stress on 
free amino acid level was compared in wild type and transgenic soybean plants transformed with cDNA coding for the last enzyme of proline biosynthesis, $\mathrm{L}-\Delta^{\prime}-$ pyrroline-5-carboxylate reductase, in sense and antisense direction. The most rapid increase in proline content was found in the sense transformants that exhibited the least water loss, while the slowest elevation of proline levels was detected in the antisense transformants that exhibited the greatest water loss during stress (SimonSarkadi et al. 2005).

\section{PHOTOSYNTHESIS}

\section{High temperature stress}

Net photosynthesis is reversibly inhibited at moderately higher temperature. Photosynthetic pigment composition and photosystem II (PS II) photochemistry gets altered during high temperature stress period. During leaf senescence, neoxanthin and $\beta$-carotene decreased concomitantly with chlorophyll, whereas lutein and xanthophyll cycle pigments were less affected. The chlorophyll a/b ratio also increased (Lu et al. 2001). Photosynthetic rates and thylakoid activities are adversely affected by high temperatures in wheat (AlKhatib and Paulsen, 1990). The photosynthetic response to high temperature included adverse association with light reactions and injury to PS II in wheat (Havaux, 1992). Recent research has shown significant variation among wheat cultivars with respect to reduction in photosynthesis at high temperature. Genotypes most tolerant to high temperatures had the most stable leaf photosynthetic rates or had longer duration of leaf photosynthetic activity after anthesis (Abrol and Ingram, 1996). High temperature enhanced light harvesting complex (LHC II) phosphorylation either because of activation of kinase or by suppression of phosphatase activity. The induced ability of LHC II for enhanced phosphorylation may enable better energy distribution in favour of photosystem I (PS I) (Satpathy and Mohanty, 2000). High temperature is known to influence the migration of LHC II (Mohanty and Vani, 2003). High temperature impacts plant biomass accumulation by altering the rate of net photosynthesis due to limiting activity of ribulose 1, 5 bisphosphate carboxylase/ oxygenase (Rubisco). The activation state of Rubisco, which is regulated by the activity of Rubisco activase, appears to be primary limitation to net photosynthesis at high temperature (Salvucci and Crafts-Brandner, 2004a). ATP pools were speculated to be compensated by increased cyclic phosphorylation by PS I or lowered usage of ATP due to deactivation of Rubisco (Salvucci and Crafts-Brandner, 2004b). High temperature decreased wheat productivity by adversely affecting photosynthetic rate and viable leaf area during maturation (Shah and Paulsen, 2005). Heat stress decreased chlorophyll content and net photosynthetic rate (Morales et al. 2003; Todorov et al. 2003). Decrease in chlorophyll content, ribulose-1, 5-bisphosphate carboxylase/oxygenase (Rubisco) binding protein, Rubisco activase was investigated in wheat leaf segments during heat stress (Demirevska-Kepova et al. 2005).

\section{Drought}

Water stress is one of the important environmental factors inhibiting the process of photosynthesis. In particular, PS II photochemistry has been shown to be very sensitive to water stress (Masojidek et al. 1991; Van Rensburg and Kruger, 1993). Several in vivo studies demonstrated that water stress damaged the oxygen evolving complex of PS II (Toivonen and Vidaver, 1988) and to the PS II reaction centres (Havaux et al. 1986, 1987). It seems such damage to PS II reaction centers was associated with the degradation of D1 protein (He et al. 1995; Giardi et al. 1996). Liang et al. (1997) have shown that drought induced decrease of photosynthesis was mainly a result of the closure of stomata caused by the increased amino butyric acid concentration in the xylem. Exposure of plants to drought led to noticeable decrease in photosynthesis rate, stomatal and mesophyll conductance and a concomitant increase in intercellular $\mathrm{CO}_{2}$ concentration (Siddique et al. 1999). Water deficit at vegetative and anthesis stage significantly reduced net photosynthesis. Stress induced reductions in photosynthetic rate were found to be up to $65 \%$ and $80 \%$ for vegetative and anthesis drought, respectively (Brar et al. 1990). Water deficit along with nitrogen deficiency strongly reduced the photosynthetic activity by decreasing the efficiency of PS II and efficiency of potential photosynthetic quantum conversions of leaves significantly (Shangguan et al. 2000). Severe drought significantly reduced photosynthesis, shoot and root biomass and root respiration rate (Liu and $\mathrm{Li}, 2005$ ).

\section{High temperature and drought stresses}

Heat and drought stress decreased photosynthetic rate, however, the decline in photosynthetic rate was more severe under heat than under drought stress during the first 12 days of treatment in Kentucky blue grass. The combined heat and drought stresses caused more dramatic reductions in photosynthetic rate than either 
heat or drought alone (Jiang and Huang, 2000). Drought decreased photosynthetic rate and high temperature hastened the decline in photosynthetic rate in wheat. Interactions between the two stresses were pronounced, and consequences of drought on all physiological parameters were more severe at high temperature than low temperature. The synergistic interactions indicated that productivity of wheat is reduced considerably more by the combined stress than by either stress alone, and much of the effect is on photosynthetic processes (Shah and Paulsen, 2003). Photosynthesis and its tolerance to photo-inhibition and high temperature and drought stress of flag leaves were investigated in wheat (Triticum aestivum L.) hybridization line (1-12) and its parents (Jing-411 and Xiaoyan-54). To characterize photooxidative damage, tolerance to photo-inhibition, high temperature and drought stress was compared in 1-12 and its parents. When exposed to high light (1400 $\mu \mathrm{mol}$ $\left.\mathrm{m}^{-2} \mathrm{~s}^{-1}\right)$, the maximal efficiency of PS II photochemistry (Fv/Fm) decreased significantly with increasing exposure time and such a decrease was much less in 1-12 than in its parents. When exposed to higher temperatures $\left(30-45{ }^{\circ} \mathrm{C}\right)$ for $15 \mathrm{~min} ., \mathrm{Fv} / \mathrm{Fm}$ started to decrease at $42{ }^{\circ} \mathrm{C}$ in $1-12$ and its parents. The greatest decrease in Fv/Fm was observed in Jing-411. 1-12 and Xiaoyan-54 showed a comparable decrease in Fv/Fm. Similar results were also observed in the actual PS II efficiency ( $\Phi$ PS II), photochemical quenching (qP) and non-photochemical quenching (qN). During exposure of detached leaves to air under room temperature conditions, relative water content decreased with increasing exposure time. However, such a decrease was the greatest in Jing-411 followed by Xiaoyan-54, and 1-12. In addition, the activities of ribulose-1, 5-bisphosphate carboxylase, phosphoenolpyruvate carboxylase, pyruvate phosphate dikinase, NADP-malate dehydrogenase and NADPmalate enzyme were significantly higher in 1-12 than in its parents. The results obtained in this study suggested that high resistance to photo-oxidative damage of the flag leaves in 1-12 may be the physiological basis for its high yield when grown in north China (Yang et al. 2006).

\section{TRANSPIRATION AND STOMATAL CONDUCTANCE}

\section{High temperature stress}

A rise in temperature due to green house effect tends to stimulation of transpiration. Evaporative demand exhibits near exponential increase with increase in daytime temperature and results in high transpiration rates and low plant water potential (Hall, 2001). Change in vapor pressure deficit at leaf surface tends to increase transpiration at higher temperatures. High temperature was found to correlate strongly with stomatal conductance and grain yield (Rekika et al. 2000). Partial stomatal closure at high temperature alleviates water stress during period of high water requirement (Geijn and Goudrian, 1996). Stomatal closure lessens the stomatal gas exchange at higher temperatures. The adaptive advantage of higher stomatal conductance appears to be associated with leaf cooling (Munjal and Dhanda, 2004). Thus stomatal conductance could be valuable selection criteria for higher yields in wheat grown at supra-optimal temperatures (Zhenmin et al. 1998).

\section{Drought}

Water stress may increase $\mathrm{pH}$ of the xylem sap before it reaches the leaves, thus it may be able to cause an increase of the apoplastic $\mathrm{pH}$ which may further induce stomatal closure (Slovic and Hartung, 1992). Backcrossing genotypes with superior transpiration efficiency into locally adapted cultivars have shown 10 per cent better yield at water limited site (Turner, 1997). Drought induced root borne signals probably control stomatal conductance and leaf extension rate during mild soil drying in the field (Ali et al. 1998).

\section{High temperature and drought stresses}

High temperature and drought often occur simultaneously, but their effects on crops have been usually investigated individually. Drought decreased stomatal conductance, viable leaf area, photosynthesis, shoot and grain mass and weight but increased plant water use efficiency in wheat. High temperature hastened the decline in photosynthesis and leaf area, decreased shoot and grain mass as well as weight and reduced water use efficiency. The interactions between the two stresses were pronounced and simultaneous drought and heat stress were more detrimental than either stress alone (Shah and Paulsen, 2005). Drought preconditioned plants maintained higher stomatal conductance, transpiration rate and photosynthesis than non-preconditioned plants during subsequent heat stress in turfgrass (Jiang and Huang, 2000).

\section{MEMBRANE THERMOSTABILITY}

\section{High temperature stress}

Thermostability of various cellular membranes is important during high temperature stress. Excessive 
fluidity of membranes due to high temperature is associated with loss of physiological functions. High temperature stress leads to increased membrane permeability and hence increased ion and solute flux (Levitt, 1980). Membrane thermostability is an important index of screening cultivars for thermo-tolerance (Blum and Ebercon, 1981; Munjal et al. 2004). Adaptations of plants to high temperature are because of functional cell membrane system during heat stress. Membrane thermostability of durum wheat is significantly greater than that of bread wheat (Galiba et al. 1997). Temperature above $30{ }^{\circ} \mathrm{C}$ causes disorientation of lamellar structure of chloroplast. Increased activity of hydrolytic enzymes promotes the rate of ion transport under heat stress conditions (Singla et al. 1997). Plants have evolved a variety of responses to elevated temperatures that minimize damage and ensure protection of cellular homeostasis. New information about the structure and function of heat stress proteins and molecular chaperones has become available. At the same time, transcriptome analysis of Arabidopsis has revealed the involvement of factors other than classical heat stress responsive genes in thermotolerance. Recent reports suggest that both plant hormones and reactive oxygen species also contribute to heat stress signaling. Additionally, an increasing number of mutants that have altered thermotolerance have extended our understanding of the complexity of the heat stress response in plants (Kotak et al. 2007). Thermo-tolerant wheat lines have higher membrane thermostability, lower internal $\mathrm{CO}_{2}$ concentration and higher rates of dark respiration than the susceptible ones (Reynolds et al. 1998). High temperature stress leads to loss of membrane integrity followed by increase in cell permeability (Taiz and Zeiger, 2002). Membrane thermostability is one of the important parameter and indicates genetic variability for heat stress (Craufurd et al. 2003).

Membrane lipid saturation is considered an important element in high temperature tolerance. In mutant wheat line with increased heat resistance, heat treatment increased relative quantities of linolenic acid among galactolipids and trans- $\Delta 3$ hexadecanoic acid among phospholipids compared with wild type wheat plants (Behl et al. 1996). Severe heat stress caused denaturation of membrane proteins and melting of membrane lipids which cause membrane rupture and loss of cellular contents (Abrol and Ingram, 1996). Heat tolerance based on membrane thermostability is a valuable supplementary criterion in final breeding stage or as a rough selection tool to reduce large population into heat tolerant core at early stages of breeding programme (Blum et al. 2001).

\section{Drought}

Bewley (1979) emphasized the critical role of cell membrane stability under conditions of moisture stress as a major component of drought tolerance. Cell membrane stability under water stress can be of possible adaptive value and indicative of drought stress tolerance (Krishnamani et al. 1984). Under extreme dehydration stress, membranes undergo a degradative process, leading to a buildup of conjugated lipids such as triglycerides, sterol esters and sterol glucosides. Water stress resulted in reduction of about 24 and $31 \%$ in total lipids and phospholipids in plasma membrane, respectively. Also the amount of glycolipids and diacylglycerols decreased significantly upon water stress (Navari-Izzo et al. 1993). Associations between osmotic adjustment and cellular membrane stability under drought stress were suggested more recently (Chandra Babu et al. 2004).

\section{High temperature and drought stresses}

Simultaneous heat and drought stress increased cell membrane permeability of perennial ryegrass (Chen et al. 1988). The interaction of heat and drought caused more rapid and severe damage of cell membrane stability than either stress alone.

\section{STEM RESERVE MOBILISATION}

\section{High temperature stress}

Stored stem reserves serve as a source of carbon for grain filling in wheat, particularly during stress conditions. The grain filling of wheat is seriously impaired by heat stress due to reductions in current leaf and ear photosynthates at high temperatures. An alternative source of carbon for grain filling is stored stem reserves. Stem may play an important role when assimilates accumulate in stem and later on retranslocate, because it may maintain reproductive growth under stress conditions (Blum et al. 1994). In wheat, peduncle and penultimate internode contained more reserve storage (Wardlaw and Willenbrink, 1994). Dry matter loss from the second internode during grain filling positively correlated with yield, mass per grain, number and mass of grains per ear and harvest index. By contrast, dry matter loss was negatively correlated with relative growth rate of main shoots during grain filling and means temperature from sowing to anthesis (Cruz-Aguado et al. 2000). 
Greater stem reserve mobilization in tolerant wheat genotypes supported grain filling during critical stage of dry matter accumulation in grain and helped in providing tolerance to post-anthesis heat stress (Shukla et al. 1997). Thermo-tolerant wheat genotypes CBW 12 and NIAW 845 showed lesser reduction in grain weight (12\%) whereas more than $30 \%$ reduction in grain weight was observed in thermo-susceptible genotypes viz. Raj 4014 and HUW 510 , conferring the role of stem reserves in grain filling. This was further supported by close association between contribution of stem reserve for grain development and depletion of soluble sugars in stem at harvest (Rane et al. 2003). The demand by grain sink was the primary factor in determining stem reserve mobilization. The interaction between ear size and demand for stem storage appeared to depend upon the environment before or during grain filling (Bonett and Incoll, 1992). The rate of stem reserve mobilization was not sufficiently high to compensate for reduction in grain filling duration at high temperature (Blum, 1998).

\section{Drought}

Yang et al. (2001) reported that 75-92 \% of pre-anthesis ${ }^{14} \mathrm{C}$ stored in the straw was reallocated to grains of wheat cultivar, Yangmai 158 and Yangmai 931 in waterdeficit treatments, 50 to $80 \%$ higher than the amount in well-watered treatments, indicating that water deficits promoted remobilization. Internode length, weight and specific weight were reduced under drought. Drought increased mobilization efficiency, expressed as percentage of maximum dry matter mobilized, in the peduncle, penultimate and the lower internodes by 65,11 and $5 \%$, respectively in wheat (Ehdaie et al. 2006).

\section{High temperature and drought stresses}

Jiang and Huang (2000) reported that drought or heat alone, or heat and drought, significantly reduced root dry weight in Kentucky blue grass. However, reduction was more severe under heat alone than under drought stress. Drought preconditioning significantly increased root dry weight as compared to non-preconditioned plants during subsequent heat stress. Simultaneous drought and heat stresses were more detrimental than either stress alone.

\section{CONCLUSIONS}

The wheat crop is grown in diverse agro-ecological conditions ranging from temperate to subtropical climates. Thus, considerable climatic differences in temperature and relative humidity exist in these areas and wheat crop experiences wide seasonal variations. High temperature hastened the decline in photosynthetic rate and viable leaf area during maturation, decreased relative water content and reduced water use efficiency. Drought increased stomatal resistance, decreased photosynthesis and enhanced water use efficiency. Recent research has shown significant variation among wheat cultivars with respect to reduction in photosynthesis at high temperature. Genotypes most tolerant to high temperatures had the most stable leaf photosynthetic rates or had longer duration of leaf photosynthetic activity after anthesis. However, high photosynthetic rates at high temperature do not necessarily support high rates of dry matter accumulation. Interactions between the two stresses were pronounced and consequences of drought on all physiological parameters were more severe at high temperature than low temperature. The synergistic interactions indicated that productivity of wheat is reduced considerably more by the combined stress than by either stress alone. Simultaneous drought and heat stresses were more detrimental than either stress alone. High-temperature stresses affects all growth stages of crops and ultimately yields. This is further aggravated by other environmental stresses like intermittent drought and high light. Management options are few and hence developing intrinsically tolerant plants is essential to combat the situation. As thermotolerance is a multigenic trait, emphasis needs to be on relevant approaches to assess genetic variability in basal and acquired tolerance. This is in fact the major aspect in crop improvement programmes (Senthil-Kumar et al. 2007). Breeding for abiotic (thermo and moisture) stress tolerance in wheat cultivars requires understanding of the physiological responses of wheat crop to these stresses, which will help in identifying traits, to be used as selection criteria.

\section{REFERENCES}

Abrol, Y.P. \& Ingram, K.T. 1996. Effects of higher day and night temperatures on growth and yield of some crop plants. In: Fakri, N. \& Wim, S. (eds.) Global Climate Change And Agricultural Production. Direct And Indirect Effects Of Hydrological Pedological And Plant Physiological Processes. John Wiley Press, England, pp. 1-14.

Acevedo, E., Nachit, M. and Ortiz, G. 1990. Effect of heat stress on wheat and possible selection tools for the use in breeding for tolerance. Wheat for the nontraditional warm areas. In: Saunders, D.A. (ed.) Proceedings of International Conference, July, 29-3, 
Aug., Mexico, pp. 401-402.

Ali, M., Jensen, C.R. \& Mogensen, V.O. 1998. Early signals in field grown wheat in response to shallow soil drying. Australian Journal of Plant Physiology, 25: $871-882$.

Al-Khatib, K. \& Paulsen, G.M. 1990. Photosynthesis and productivity during high temperature stress of wheat genotypes from major world regions. Crop Science, 3: 1127-1132.

Ashraf, M., Saeed, M.M. \& Qureshi, M.J. 1994. Tolerance to high temperature in cotton (Gossypium hirsutum L.) at initial growth stages. Environmental and Experimental Botany, 30: 515-524.

Aspinall, D. \& Paleg, L.G. 1981. Proline accumulation : Physiological aspects. In: Paleg, L.G. \& Aspinall, D. (eds.) Physiology and Biochemistry of Drought Resistance in Plants. Academic Press, New York, pp. 205-207.

Behl, R.K., Heise, K.P. \& Maowad, A.M. 1996. High temperature tolerance in relation to changes in lipids in mutant wheat. Tropenlandwirt, 97: 131-135.

Behl, R.K., Moawad, A.M. \& Achtmich, W. 1991. Amino acid and protein profile changes in spring wheat mutant under prolonged heat stress. Annals of Biology, 7: 63-67.

Bewley, J.D. 1979. Physiological aspects of desiccation tolerance. Annual Review of Plant Physiology, 30: 195-228.

Blum, A. \& Ebercon, A. 1981. Cell membrane stability as a measure of drought and heat tolerance in wheat. Crop Science, 21: 43-47.

Blum, A. 1998. Improving wheat grain filling under stress by stem reserve mobilization. In: Brawn, H.J., Altay, F., Kronstad, W.E., Beniwal, S.P.S. \& McNab, A. (eds.) Wheat Prospects For Global Improvement. Kluwer Academic Publishers, Netherland, pp. 135-141.

Blum, A. 2005. Drought resistance, water use efficiency and yield potential- are they compatible, dissonaut, or mutually exclusive? Australian Journal of Agricultural Research, 56: 1159-1168.

Blum, A., Klueva, N. \& Nguyen H.T. 2001. Wheat cellular thermo-tolerance is related to yield under heat stress. Euphytica, 117: 117-123

Blum, A., Sinmena, B., Mayer, J., Golan, G. \& Shpiler, L. 1994. Stem reserve mobilization supports wheat grain filling under heat stress. Australian Journal of Plant Physiology, 21: 771-781.

Bonnet, G.D. \& Incoll, L.D. 1992. Effects on stem of winter barley on manipulating the source and sink during grain filling: Changes in accumulation and loss of mass from internodes. Journal of Experimental Botany, 44: 75-82.

Brar, G.S., Kar, S. \& Singh, N.T. 1990. Photosynthetic response of wheat to soil water deficit in the tropics. Journal of Agronomy and Crop Science, 164: 343-348.

Chandra Babu, R., Zhang, J. X., Blum, A., Ho, D. T-H., Wu, R. \& Ngugen, H.T. 2004. HVA1, a LEA gene from barley confers dehydration tolerance in transgenic rice (Oryza sativa L.) via cell membrane protection. Plant Science, 166: 855-862.

Chen, C.F., Liang, Z.D. \& Wang, H.S. 1988. Physiological responses of perennial rye grass to high temperature and drought. Journal of Nanjiang Agricultural University, 11: 87-92.

Clarke, J.M. \& Towney-Smith, T.F. 1986. Heritability and relationships of yield with excised leaf water retention in durum wheat. Crop Science, 26: 289-292.

Clarke, J.M. 1987. Use of physiological and morphological traits in breeding programmes to improve drought resistance of cereal. In: Srivastava, J.P., Porceddu, E., Acevedo, E. \& Verma, S. (eds.) Drought tolerance in winter cereals. John Wiley and Sons, New York, pp. 171-190.

Clarke, J.M. \& Richards, R.A. 1988. The effect of glaucousness, epicuticular wax, leaf age, plant height and growth environment on water loss rates of excised wheat leaves. Canadian Journal of Plant Science, 68: 975-982.

Craufurd, P.O., Prasad, P.V.V., Kakani, V.G., Wheeler, T.R. \& Nigam, S.O. 2003. Heat tolerance in groundnut. Field Crops Research, 80: 63-77.

Cruz-Aguado, J.A., Rodes, R., Perez, I. \& Dorado, M. 2000. Morphological characteristics and yield components associated with accumulation and loss of dry mass in the internodes of wheat. Field Crops Research, 66: 129-139.

Demirevska-Kepova, K., Holzer, R., Simova-Stoilova, L. \& Feller, U. 2005. Heat stress effects on ribulose1,5-bisphosphate carboxylase/oxygenase, Rubisco binding protein and Rubisco activase in wheat leaves. Biologia Plantarum, 49: 521-525.

Deng, X-P., Lun, S., Shinobu, I. \& Mitsuhiro, I. 2005. Water saving approaches for improving wheat production. Journal of Science of Food and Agriculture, 85: 1379-1388.

Dhanda, S.S. \& Sethi, G.S. 1998. Inheritance of excised- 
leaf water loss and relative water content in bread wheat (Triticum aestivum). Euphytica, 104: 39-47.

Dhanda, S.S. \& Sethi, G.S. 2004. Index of drought resistance in relation to water retention parameters in bread wheat. Annals of Agricultural Research New Series, 25: 211-214.

Dhanda, S.S. 1993. Studies on genetics of morphological and biochemical characters associated with drought tolerance in wheat (Triticum aestivum L.). Ph.D. Thesis submitted to H.P. Agricultural University, Palampur (H.P.), India.

Dhanda, S.S., Behl, R.K. \& Eibassam, N. 1995. Breeding wheat genotypes for water deficit environments. Landbauforshung Volkenrode, 45: 159-167.

Dhanda, S.S., Behl, R.K, Shinano, T. \& Osaki, M. 2007. Wheat improvement under Water deficit conditions in semi arid tropics and sub tropics. Tropics, 16: 75-84

Dhanda, S.S., Sethi, G.S. \& Behl, R.K. 1998. Excised leaf water loss as a simple selection criterion for drought resistance in wheat. Der Tropen Landwirt, 99: 3-8.

Ehdaie, B., Alloush, G.A., Madore, M.A. \& Waines, J.G. 2006. Genotypic variation for stem reserves and mobilization in wheat: I. Post-anthesis changes in Internode dry matter. Crop Science, 46: 735-746.

Galiba, G., Nagy, Z., Janda, T., Szente, K., Csintation, Z., Turberosa, R., Monneveus, P. \& Coumans, M. 1997. Heat stress induced differential alternations in the photosynthesis, membrane thermostability and biomass production of bread and durum wheat varieties. Acta Agronomica Hungarica, 45: 1-15.

Geijn, S.C.V.D. \& Goudrian, J. 1996. The effects of elevated $\mathrm{CO}_{2}$ and temperature change on transpiration and crop water use. In: Fakri, B. \& Wim, S. (eds.) Global Climate Change And Agricultural Production. Direct And Indirect Effects Of Changing Hydrological, Pedological And Plant Physiological Processes. John Wiley Press, England

Giardi, M.T., Cona, A., Geiken, B., Kucera, T., Masojidek, J. \& Mattoo, A.K. 1996. Long term drought stress induces structural and functional re-organization of photo-system. II. Planta, 199: 118-125.

Gilliham, M. \& Tester, M. 2005. The regulation of anion loading to the maize root xylem. Plant Physiology, 137: 819-828.

Hall, A.E. 2001. Crop response to environment, CRC Press, LLC, Boca Raton, Florida.

Havaux, M. 1992. Stress tolerance of photosystem II in vivo. Antagonist effects of water, heat and photo- inhibition stress. Plant Physiology, 100: 424-432.

Havaux, M., Canaani, O. \& Malkin, S. 1986. Photosynthetic responses of leaves to water stress, expressed by photoacoustic and related method. Plant Physiology, 82: 827-833.

Havaux, M., Canaani, O. \& Malkin, S. 1987. Inhibition of photosynthetic activities under slow water stress measured in vivo by the photoacoustic method. Physiologia Plantarum, 70: 503-510.

He, J.X., Wang, J. \& Liang, H.G. 1995. Effects of water stress on photochemical function and protein metabolism of photosystem II in wheat leaves. Physiologia Plantarum, 93: 771-777.

Howard, A. 1924. Crop production in India : A critical survey of its problem. Oxford University Press.

Jiang, Y. \& Huang, B. 2000. Effects of drought or heat stress alone and in combination on Kentucky bluegrass. Crop Science, 40: 1358-1362.

Knipp, G. \& Honermeier, B. 2006. Effect of water stress on proline accumulation of genetically modified potatoes (Solanum tuberosum L.) generating fructans. Journal of Plant Physiology, 163: 392-397.

Kotak, S., Larkindale, J., Lee, U., Koskull-Doring, P.V., Vierling, E. \& Scharf, K.D. 2007. Complexity of heat stress response in plants. Current Opinion in Plant Biology, 10: 310-316.

Krishnamani, M.R.S., Yopp, J.H. \& Myers, O. 1984. Leaf solute leakage as a drought tolerance indicator in soybean. Phyton, 44: 43-49.

Laurie, S., Feeney, K.A., Maathis, F.J.M., Heard, P.J., Brown, S.J. \& Leigh, R.A. 2002. A role for HKT1 in sodium uptake by wheat roots. The Plant Journal, 32: 139-149.

Levitt, J. 1980. High temperature stress. In: Responses of plants to environmental stresses (Vol. I). Academic Press. INC, London, pp. 347-391.

Liang, J., Zhang, J. \& Wong, M. 1997. Can stomatal closure caused by xylem ABA explain the inhibition of leaf photosynthesis under soil drying. Photosynthesis Research, 51: 149-159.

Lilley, J.M. \& Ludlow, M.W. 1996. Expression of osmotic adjustment and dehydration tolerance in diverse rice lines. Field Crops Research, 48: 185-197.

Liu, H.S. \& Li, F.M. 2005. Root respiration, photosynthesis and grain yield of two spring wheat in response to soil drying. Plant Growth Regulation, 46: $233-240$.

Lu, C., Lu, Q., Zhang, J. \& Kuang, T. 2001. Characterization of photosynthetic pigment composition, photosystem II photochemistry and 
thermal energy dissipation during leaf senescence of wheat plants grown in the yield. Journal of Experimental Botany, 52: 1805-1810.

Machado, S. \& Paulsen, G.M. 2001. Combined effect of drought and high temperature on water relation of wheat and sorghum. Plant and Soil, 233: 179-187.

Masojidek, J., Trivedi, S., Halslaw, L., Alexiou, A. \& Hall, D.O. 1991. The synergistic effect of drought and light stresses in sorghum and pearl millet. Plant Physiology, 96: 198-207.

McCaig, T.N. \& Ramagosa, I. 1991. Water status measurements of excised leaves : Position and age effects. Crop Science, 31: 1583-1588.

Mohanty, P. \& Vani, B. 2003. Stress triggered phosphorylation and migration of light harvesting complex of PS II. Indian Journal of Plant Physiology, (Special issue): 178-185.

Morales, D., Rodrigues, P., Dell' Amico, J., Nicolas, E., Torrecillas, A. \& Sanchez-Blanco, M.J. 2003. High temperature preconditioning and thermal shock imposition affects water relations, gas exchange and root hydraulic conductivity in tomato. Biologia Plantarum, 47: 203-208.

Munjal, R. \& Dhanda, S.S. 2004. Physiological and morphological traits associated in bread wheat under heat stress. In: Proceedings of $91^{\text {st }}$ Indian Science Congress Part III (Advance abstracts). 1-3 $3^{\text {rd }}$ January, P.U. Chandigarh, India.

Munjal, R., Dhanda, S.S., Rana, R.K. \& Singh, I. 2004. Membrane thermostability as an indicator of heat tolerance at seedling stage in bread wheat. National Journal of Plant Improvement, 6: 133-135.

Navari-Izzo, F., Quartacci, M.F., Melfi, D. \& Izzo, R. 1993. Lipid compositionof plasma membranes isolated from sunflower seedlings grown under water stress. Physiologia Plantarum, 87: 508-514.

Nayyar, H. \& Walia, D.P. 2003. Water stress induced proline accumulation in contrasting wheat genotypes as affected by calcium and abscisic acid. Biologia Plantarum, 46: 275-279.

Rane, J., Chauhan, H. \& Shoran, J. 2003. Post-anthesis stem reserve mobilization in wheat genotypes tolerant and susceptible to high temperature. Indian Journal of Plant Physiology, (Special issue): 383-385.

Rekika, D., Kara, Y., Souyris, I., Nachit, M.M., Asbati, A. \& Monneveny, P. 2000. The tolerance of PS II to high temperature in durum wheat (T. turgidum conv. durum) : genetic variation and relationship between yield under heat stress. Cereal Research
Communications, 28: 395-402.

Reynolds, M.P., Ortiz-Monasterio, J.I. \& McNab, A. (eds.). 2001. Application of physiology in wheat breeding. Mexico, D.F.: CIMMYT.

Reynolds, M.P., Singh, R.P., Ibrahim, A., Ageeb, O.A.A., Saovedra, A.L. \& Quick, J.S. 1998. Evaluating physiological traits to complement empirical selection of wheat in warm environments. In: Braun, H.J (ed.) Wheat Prospects For Global Improvement. Kluwer Academic Publisher, Netherlands, pp. 143-152.

Roosens, N.H., Al Bitar, F., Loenders, K., Angenon, G. \& Jacobs, M. 2002. Over expression of ornithine$\Delta$-amino-transferase increases pro biosynthesis and confers osmotolerance in transgenic plants. Molecular Breeding, 9: 73-80.

Salvucci, M.E. \& Crafts-Brandner, S.J. 2004a. Relationships between heat tolerance of photosynthesis and the thermal stability of Rubisco activase in plants from contrasting thermal environments. Plant Physiology, 134: 1460-1470.

Salvucci, M.E. \& Crafts-Brandner, S.J. 2004b. Inhibition of photosynthesis by heat stress. The activation state of Rubisco as a limiting factor in photosynthesis. Physiologia Plantarum, 120: 179-186.

Satpathy, M. \& Mohanty, P. 2000. Effects of high temperature exposure of spinach intact plants and isolated thylakoids on light harvesting complex II protein phosphorylation. Biologia Plantarum, 43: 433-435.

Senthil-Kumar, M., Kumar, G., Srikanthbabu, V. \& Udayakumar, M. 2007. Assesment of variability in acquired thermotolerance : Potential option to study genotypic response and relevance of stress genes. Journal of Plant Physiology, 164: 111-125.

Shah, N.H. \& Paulsen, G.M. 2003. Interaction of drought and high temperature on photosynthesis and grain filling of wheat. Plant and Soil, 257: 219-226.

Shah, N.H. \& Paulsen, G.M. 2005. Injury to photosynthesis and productivity from interaction between high temperature and drought during maturation of wheat. Asian Journal of Plant Science, 4: $67-74$.

Shah, N.H. 1992. Responses of wheat to combined high temperature and drought or osmotic stresses during maturation. Dissertation Abstract International-B,Science and Engineering. 52: 3984B.

Shangguan, Z., Shao, M. \& Dyckmans, J. 2000. Effects of nitrogen nutrition and water deficit on net photosynthetic rate and chlorophyll fluorescence 
in winter wheat. Journal of Plant Physiology, 156: $46-51$.

Shukla, D.S., Gupta, N.K., Kapashi, S.B., Deshmukh, P.S., Sairam, R.K. \& Pande, P.C. 1997. Relationship between stem reserves and grain development in terminal heat stress susceptible and tolerant wheat genotypes. Indian Journal of Plant Physiology, 2: 36-40.

Siddique, M.R.B., Hamid, A. \& Islam, M.S. 1999. Drought stress effects on photosynthetic rate and leaf gas exchange of wheat. Botanical Bulletin of Academia Sinica, 40: 141-145.

Simon-Sarkadi, L., Kocsy, G., Varhegyi, A., Galiba, G. \& De Ronde, J.A. 2005. Genetic manipulation of proline accumulation influences the concentrations of other amino acids in soybean subjected to simultaneous drought and heat stress. Journal of Agricultural and Food Chemistry, 53: 7512-7517.

Sinclair, T.R. \& Ludlow, M.M. 1986. Influence of soil water supply on the plant water balance of four tropical grain legumes. Australian Journal of Plant Physiology, 13: 329-341.

Singh, R.P., Vara Prasad, P.V., Sunita, K., Giri, S.N. \& Raja Reddy, K. 2007. Influence of high temperature and breeding for heat tolerance in cotton. A Review. Advances in Agronomy, 93: 313-385.

Singla, S.L., Parek, A. \& Grover, A. 1997. High temperature. In: Prasad, M.N. (ed.) Plant Ecophysiology. John Wiley and Sons, New York, pp. 101-106.

Slovic, S. \& Hartung, W. 1992. Compartmental distribution of $\mathrm{ABA}$ in intact leaves III: Analysis of the stress signal chain. Planta, 187: 37-47.

Stone, P.J. \& Nicolas, M.E. 1995. Effects of timing of heat stress during grain filling on two wheat varieties differing in heat tolerance. 1. Grain growth. Australian Journal of Plant Physiology, 22: 927-934.

Taiz, L. \& Zeiger, E. 2002. Plant Physiology. Sinuaer associates incorporation publishers, Saunderland, Manchuessets.

Todorov, D.T., Karanov, E.N., Smith, A.R. \& Hall, M.A. 2003. Chlorophyllase activity and chlorophyll content in wild type and eti 5 mutant of Arabidopsis thaliana subjected to low and high temperatures. Biologia Plantarum, 46: 633-636.

Toivonen, P. \& Vidaver, W. 1988. Variable chlorophyll a fluorescence and $\mathrm{CO}_{2}$ uptake in water stressed white spruce seedlings. Plant Physiology. 86: 744-748.

Turner, N.C. 1997. Further progress in crop water relations. Advances in Agronomy, 58: 293-338.
Van Rensburg, L. \& Kruger, G.H.J. 1993. Differential inhibition of photosynthesis (in vivo and in vitro), and changes in chlorophyll a fluorescence induction kinetics of four tobacco cultivars under drought stress. Journal of Plant Physiology, 141: 357-365.

Wardlaw, I.F. \& Willenbrink, J. 1994. Carbohydrate storage and mobilization by the culm of wheat between heading and grain maturity: relation to sucrose synthase and sucrose-phosphate synthase. Australian Journal of Plant Physiology, 21: 255-271.

Yang, J., Zhang, J., Wang, Z., Zhu, Q. \& Liu, L. 2001. Water deficit induced senescence and its relationship to the remobilization of pre-stored carbon in wheat during grain filling. Agronomy Journal, 93: 196-206.

Yang, X., Chen, X., Ge, Q., Li, B., Tong, Y., Zhang, A., Li, Z., Kuang, T. \& Lu, C. 2006.Tolerance of photosynthesis to photoinhibition , high temperature and drought stress in flag leaves of wheat: A comparison between a hybridization line and its parents grown under field conditions. Plant Science, 171(3): 389-397.

Zhenmin, L., Percy-Richard, G., Qualset, O. \& Zeiger, E. 1998. Stomatal conductance predicts yield in pima cotton and bread wheat grown at high temperature. Journal of Experimental Botany, 49: 453-460.

Received $8^{\text {th }}$ Nov. 2007 Accepted $23^{\text {rd }}$ Jan. 2008 